\title{
Signaling from Epithelial to Dendritic Cells of the Thyroid Gland: Evidence for Thyrocyte-Derived Factors Controlling the Survival, Multiplication, and Endocytic Activity of Dendritic Cells
}

\author{
Karine Croizet, Séverine Trouttet-Masson, Rachida Rabilloud, \\ Jean-Francois Nicolas, Françoise Bernier-Valentin, and Bernard Rousset
}

INSERM U-369, Faculté de Médecine Lyon-RTH Laennec, Lyon, France

\begin{abstract}
SUMMARY: Intrathyroidal dendritic cells (DC) isolated at the same time and then cultured with thyrocytes in the presence of thyrotropin (TSH) keep a phenotype of immature DC (Croizet et al, 2000). As DC from other sources are known to undergo a rapid maturation in vitro, we hypothesized that the maintenance of thyroid-derived DC in an immature state might be caused by thyrocytes-DC interactions. In this study, we investigated whether thyroid-derived DC could change their phenotype in response to TSH stimulation of thyrocytes.Over an 8-day period of culture, the population of DC increased 2- to 3-fold in the presence of TSH and decreased by more than $75 \%$ in the absence of TSH. The increase in the DC population was related to DC proliferation, whereas the reduction of the number of DC was secondary to a loss of cell-substrate adhesion and subsequent cell death. In the presence of TSH, DC acquired and maintained a high capacity for internalizing labeled ligands, expressed the mannose receptor, and exposed MHC class II molecules at the cell surface. On the contrary, DC cultured without TSH were devoid of endocytic activity and mannose receptor and, after 2 days, no longer exposed MHC class II molecules at the cell surface. Using conditioned media and enriched DC populations, we show that thyrocytes, in response to TSH, produce soluble factors capable of activating proliferation and endocytic activity of DC. Exogenous granulocyte/macrophage-colony stimulating factor and transforming growth factor- $\beta$, known to be produced by thyrocytes, reproduced the effects of conditioned media. These data, giving evidence of a hormone-regulated signaling process between epithelial and dendritic cells in vitro, suggest that thyrocytes could promote the maintenance of a population of immature DC within the thyroid gland. (Lab Invest 2001, 81:1601-1613).
\end{abstract}

$D$ endritic cells (DC) are professional antigenpresenting cells. Scattered all over the body in lymphoid as well as in nonlymphoid organs, DC are specialized to initiate primary immune responses and are involved in various physiological and pathological processes including autoimmune diseases. To fully perform their functions, DC need to be present in various differentiation states. In peripheral tissues, DC are immature and equipped to internalize and process large amounts of antigens, whereas in lymphoid organs, where they migrate, DC are mature and specialized for T cell stimulation (Banchereau et al, 2000; Banchereau and Steinman, 1998; Hart, 1997; Steinman, 1991). Information on DC mostly arises from DC generated from bone marrow or blood cell precursors (Caux et al, 1992; Inaba et al, 1992; Sallusto and Lanzavecchia, 1994). DC from nonlymphoid organs are difficult to isolate, because they represent a very small cell population. Only DC from skin and lung tissues have been successfully isolated and subjected to detailed in vitro analyses (Cochand et al, 1999;

Received June 4, 2001

Address reprint requests to: Dr. Bernard Rousset, INSERM U369, Faculté de Médecine Lyon-RTH Laennec, 7, Rue Guillaume Paradin, 69372 LYON Cedex 08, France. E-mail: u369@laennec.univ-lyon1.fr
Heufler et al, 1988; Koch et al, 1990; Masten and Lipscomb, 1999; Ortner et al, 1996). We recently reported a procedure for the isolation of DC from another nonlymphoid organ, the thyroid gland, which is particularly subjected to autoimmune processes (Croizet et al, 2000). Intrathyroidal DC, isolated simultaneously with thyrocytes from pig thyroid gland, accounted for $2 \%$ to $3 \%$ of the total cell population. Thyroid-derived DC, maintained in culture with thyrocytes in the presence of thyrotropin (TSH), kept a phenotype of immature DC. Only a small proportion of cells showed signs of conversion from immature to mature DC. As DC from other sources, especially DC from skin, rapidly undergo maturation in vitro, we suspected that the maintenance of the immature phenotype of thyroid-derived DC might be linked to the presence and/or to the activation state of thyrocytes. Here we report that, depending on the presence or the absence of TSH, thyroid-derived DC cocultured with thyrocytes undergo marked phenotypic changes. The TSH-induced effects are mediated by soluble factors produced by thyrocytes that regulate survival and/or proliferation and a differentiated activity of DC, ie, mannose receptor-mediated endocytosis. These data uncover a signaling pathway from thyrocytes to DC that might be of importance for the local control of immune functions of intrathyroidal DC. 


\section{Results}

Identification and Quantification of Dendritic Cells (DC) in Coculture with Thyrocytes

Thyroid-derived DC, ie, DC isolated together with thyrocytes from pig thyroid tissue, accounted, on average, for $2 \%$ to $3 \%$ of the total cell population. When cocultured with thyrocytes in the presence of TSH, which promotes de novo formation of tissuespecific structures, namely thyroid follicles (Fig. 1A), DC spread on the culture substratum in between follicles. DC were recognizable under phase contrast optics on the basis of their morphology; part of them were round and exhibited membrane ruffles with spikes, the others were elongated and characterized by large lamellipodiae and sometimes long cytoplasmic projections resembling dendrites. These two main cell types can be visualized in Figure 1A ( $a$ and $c$ ). That these cells actually corresponded to DC was demonstrated by endocytosis of a fluorescein-labeled Dextran (F-Dx) and by immunodetection of specific markers. Panels $b$ and $d$ of Figure $1 \mathrm{~A}$ show that cells of either morphotype were endowed with a high capacity to internalize the fluorescent ligand, F-Dx, and highly expressed MHC class II molecules. We previously reported (Croizet et al, 2000) that these cells were, in addition, S100-positive (a specific marker of DC) and expressed the mannose receptor.

When DC/thyrocytes were cocultured in the absence of $\mathrm{TSH}$, thyrocytes formed a confluent monolayer, and, consequently, DC were not easily detectable under phase contrast optics; their identification required immunolabelings. Panels e and $f$ of Figure $1 \mathrm{~A}$ illustrate the position of a DC (MHC class II-positive cell) within the cell layer. Attempts to identify DC in cocultures carried out in the absence of $\mathrm{TSH}$, on the basis of their endocytic activity, were unsuccessful. Thus, it was decided to perform a comparative analysis of the properties of thyroid-derived DC cultured with or without TSH. Results reported in Figure 1B give the properties of DC after 4 days of culture. In cocultures carried out in the presence of $\mathrm{TSH}$, the number of cells expressing MHC class II molecules, the $\mathrm{S} 100$ protein, or the mannose receptor and the number of cells internalizing F-Dx were not statistically different, as was expected from our previous findings (Croizet et al, 2000). On the contrary, when cocultures were performed in the absence of TSH, there was a decrease in the number of cells positive for either $\mathrm{MHC}$ class II or $\mathrm{S} 100$ and a large reduction $(80 \%$ to $90 \%$ ) of the number of cells internalizing F-Dx or expressing the mannose receptor. These observations, suggesting alterations of DC number and functions, prompted us to perform a detailed analysis of how DC could change their phenotype in response to TSH stimulation of thyrocytes.

\section{In the Presence of TSH-Activated Thyrocytes, DC Remain Adherent to the Culture Substratum and Proliferate}

Figure 2 shows the time-dependent changes in the number of DC (MHC class II-positive cells) over an
A
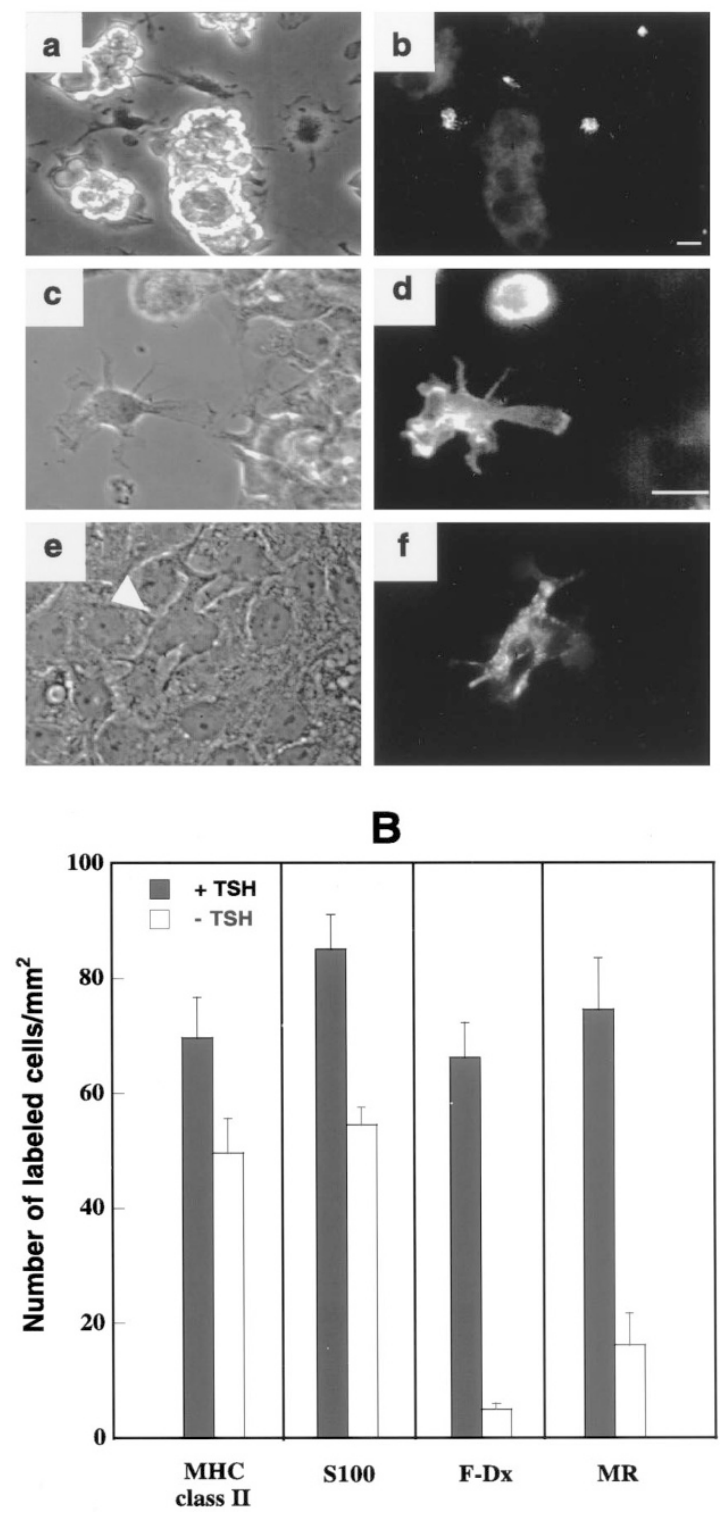

Figure 1.

Detection and quantitative analyses of dendritic cells (DC) cocultured with thyrocytes in the absence or in the presence of thyrotropin (TSH). Freshly isolated cells (DC and thyrocytes in a 1-to-50 ratio) were cultured with or without $1 \mathrm{mU} / \mathrm{ml} \mathrm{TSH}$ for 4 days. Cells were then incubated with fluoresceinlabeled Dextran (F-Dx) for 3 hours at $37^{\circ} \mathrm{C}$ and then fixed, permeabilized, and subjected to indirect immunofluorescence labeling with monoclonal antibodies directed against either the mannose receptor, MHC Class II molecules, or $\mathrm{S} 100 \beta$ protein. Immune complexes were detected using goat anti-mouse IgG conjugated to Texas Red. A (a and b), Identification of DC cocultured with thyrocytes in the presence of TSH as cells with a high capacity for internalizing F-Dx. a and b, The phase contrast and fluorescence images of the same field. Note the distribution of DC in between reconstituted thyroid follicle structures. $A$ (c to $f$ ), Characterization of DC cocultured with thyrocytes in the presence (c and $d$ ) or in the absence (e and f) of TSH as MHC class II-positive cells. $c$ to $f$, Phase contrast images and corresponding immunofluorescence labelings. DC have different morphotypes; they appear as round or elongated cells. Bars: $10 \mu \mathrm{m}$. B, Changes in the number of DC according to culture conditions: absence (open columns) or presence (closed columns) of TSH. DC identified as MHC class II-positive cells, S100-positive cells, F-Dx labeled cells, or mannose receptor-positive cells were counted on 10 microscope fields per dish. Values were used to calculate the number of labeled cells per $\mathrm{mm}^{2}$. Columns and vertical bars represent the mean and SEM of measurements from 3 or 4 dishes. 
8-day period of coculture with thyrocytes in the presence of or in the absence of TSH. In the presence of $\mathrm{TSH}$, the number of $\mathrm{DC}$ remained rather constant for 4 days then increased about 2-fold. In the absence of $\mathrm{TSH}$, the number of DC continuously decreased from Day 1 to Day 7 or 8 to reach a value corresponding to $25 \%$ of the initial cell number. It is noteworthy that DC identified after 6 to 8 days of culture, in the absence of $\mathrm{TSH}$, were predominantly large cells with cytoplasmic extensions resembling dendrites. During the same period of time, the total cell population (given by the number of Hoechst-labeled nuclei), in which thyrocytes represented $97 \%$ or more, remained constant in the presence of TSH and significantly increased (1.5fold) in the absence of TSH (Fig. 2B).

The increase in the DC population in TSH-treated cocultures was due to an activation of DC multiplication (Fig. 3). At Day 4, a 6 hour-incubation with

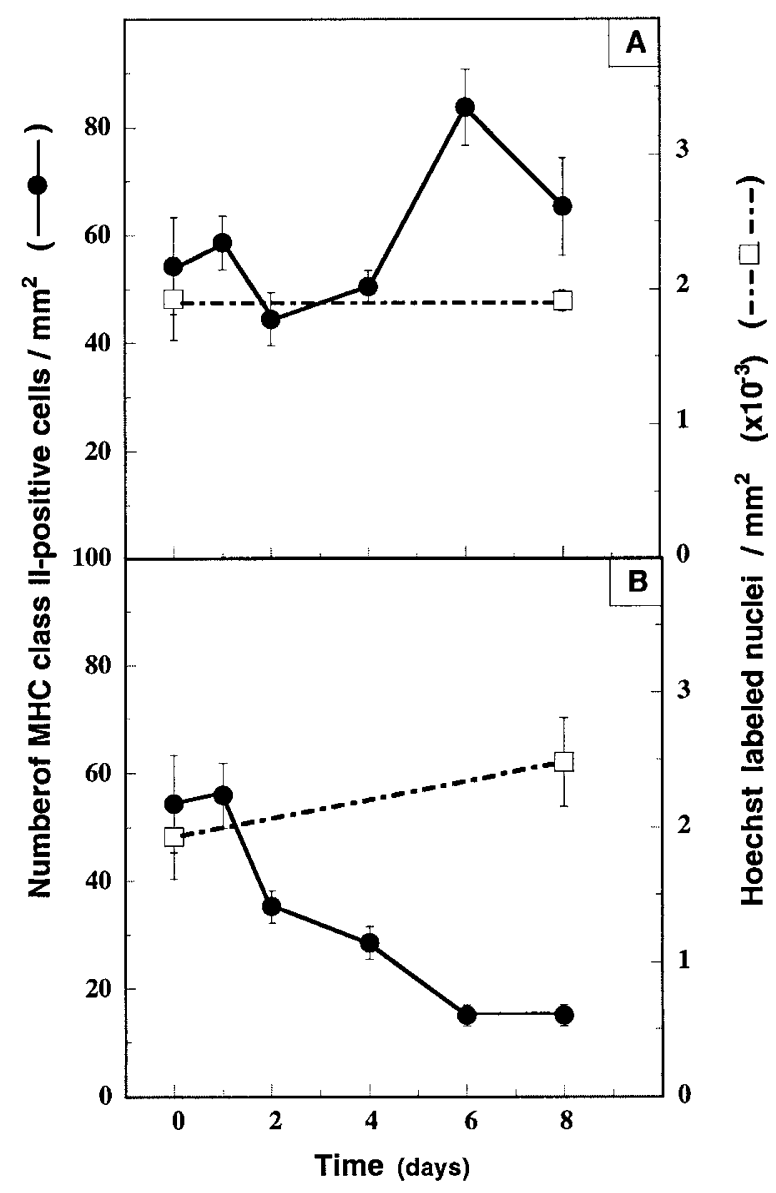

Figure 2.

Gradual changes of the DC population over an 8-day period of coculture with thyrocytes in the presence or in the absence of TSH. Freshly isolated cells, seeded at a density of $0.5 \times 10^{6}$ cells $/ \mathrm{cm}^{2}$, were cultured for up to 8 days in Ham's F12 medium with (A) or without (B) $1 \mathrm{mU} / \mathrm{ml} \mathrm{TSH}$. At the indicated times, cells were fixed and subjected to indirect immunofluorescence labeling using the anti-MHC class II monoclonal antibody. Immune complexes were detected with goat anti-mouse IgG conjugated to Texas Red and nuclei were labeled using the Hoechst 33342 reagent. MHC class II-positive cells and Hoechst-labeled nuclei were counted on 10 microscope fields per dish. The resulting values were used to calculate the number of MHC class II-positive cells or DC per $\mathrm{mm}^{2}$ (closed circles) and the total number of cells per $\mathrm{mm}^{2}$ (open squares). Results are the mean \pm SEM of measurements from 4 dishes. bromodeoxyuridine (BrdU) led to the nuclear labeling of about $30 \%$ of DC and only $0.2 \%$ of thyrocytes. Thus, the proliferation index of DC was more than 100 -fold higher than that of thyrocytes. DC that entered the $\mathrm{S}$ phase of the cell cycle could be unequivocally identified (Fig. 3C) because of their peculiar morphology and their location between reconstituted follicles. We previously reported (Croizet et al, 2000) that, under similar conditions (coculture with TSH), a small proportion of DC detached from the culture dish. We examined whether the reduction of the DC population observed in the absence of TSH could be related to an augmentation of cell detachment. Results presented in Figure 4A show that DC, collected in the medium after 4 days of culture in the presence of TSH, accounted for less than $13 \%$ of total DC. When the culture was carried out in the absence of $\mathrm{TSH}$, the total number of DC in the culture dishes was decreased, and floating DC represented almost $40 \%$ of the remaining cell population. Morphological examinations of floating MHC class II-positive cells revealed that a number of them had a fragmented nucleus (Fig. $4 \mathrm{~B}$ ), a definite feature of cells undergoing apoptosis. We roughly estimated that DC showing signs of apoptosis could represent up to one fourth of DC present in the culture medium at a given time.

\section{In the Presence of TSH-Activated Thyrocytes, DC Express the Mannose Receptor and Exhibit a High Endocytic Activity}

In a previous study (Croizet et al, 2000), we found that DC, which were mannose receptor-positive within the intact thyroid tissue transformed into mannose receptor-negative cells after cell dispersion, when analyzed by either immunofluorescence labeling or western blot. This was the result of the proteolytic cleavage of the extracellular domain of the receptor by trypsin used for cell isolation. Indeed, the mannose receptor is particularly susceptible to proteolytic cleavage. A natural process of shedding, which leads to the generation of a soluble form of the receptor, has been well documented (Jordens et al, 1999; MartinezPomares et al, 1998). Thyroid-derived DC, cocultured with thyrocytes in the presence of TSH, re-expressed the mannose receptor as a $175 \mathrm{kDa}$ protein. De novo synthesized receptors were hardly detectable before two days of culture. From Day 2, the mannose receptor cell content continuously increased (Insert of Fig. 5A). Mannose receptor-positive cells were detected by indirect immunofluorescence two days after the culture outset and, at Day 4, all DC (MHC class II-positive cells) were mannose receptor-positive. When DC were cultured in the absence of TSH, the mannose receptor was never detected by western blot (Insert of Fig. 5B) and only a few cells exhibited a low labeling by indirect immunofluorescence (result not shown). DC, devoid of endocytic activity before culture, gradually acquired the capacity for internalizing F-Dx when the coculture was performed in the presence of TSH (Fig. 5A). At Day 4, $100 \%$ of MHC class II-positive cells exhibited a high endocytic activity (Fig. 

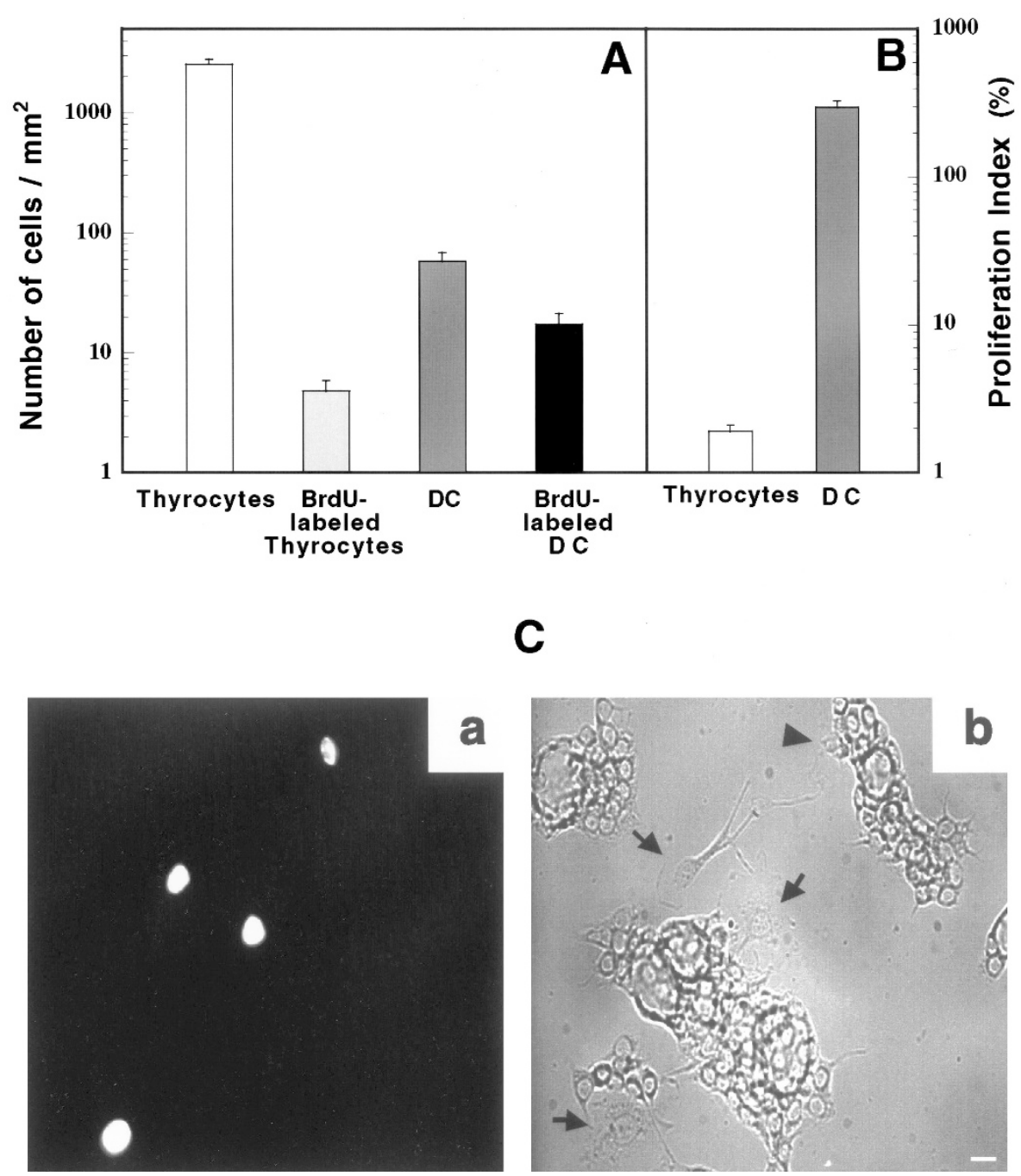

Figure 3.

Evidence for a proliferation of DC cocultured with thyrocytes in the presence of TSH. After 4 days of culture, cells were washed and further cultured for 6 hours in serum-free RPMI medium containing $1 \mathrm{mU} / \mathrm{ml} \mathrm{TSH}$ and $3 \mu \mathrm{g} / \mathrm{ml}$ bromodeoxyuridine (BrdU). At the end of the incubation period, cells were fixed and immunolabeled using either the anti-BrdU monoclonal antibody or the anti-MHC class II monoclonal antibody. BrdU-labeled cells, MHC class II-positive cells, and Hoechst-labeled nuclei were counted in 20 microscope fields. BrdU-labeled cells observed under phase contrast optics were classified as thyroid cells or DC according to their morphological characteristics. Values were used to calculate the number of labeled cells (ie, thyrocytes), BrdU-labeled thyrocytes, DC, and BrdU-labeled DC per mm² (A). A proliferative index representing the percentage of BrdU-labeled cells was calculated for thyrocytes and DC; results are given in panel B. C, The fluorescence (a) and phase contrast (b) images of a microscope field where BrdU-labeled cells: DC (arrows) and a thyrocyte (arrow head) can be identified. Bar: $10 \mu \mathrm{m}$.

6, A and C). The capacity of endocytosis of DC probably increased between Day 4 and Day 8 , because there was a marked increase in the mannose receptor expression level. However, this was not verified experimentally, because the procedure used to assess endocytosis, internalization of a fluorescent ligand, did not allow one to make quantitative measurements of the endocytic activity of the DC population. On the contrary, when DC/thyrocyte cocultures were performed in the absence of $\mathrm{TSH}$, DC remained without any detectable endocytic activity (Figs. 5B and $6, \mathrm{C}$ and D) throughout the 8-day period of culture.

\section{In the Presence of TSH-Activated Thyrocytes, DC Expose MHC Class II Molecules at the Cell Surface}

MHC class II molecules are subject to bidirectional transport between intracellular compartments and the cell surface of DC (Cella et al, 1997; Pierre et al, 1997). According to the activation or functional state of DC, MHC class II molecules are predominantly or exclusively present in intracellular compartments or also exposed at the cell surface. We analyzed whether thyroid-derived DC exhibited changes in the subcellular distribution of MHC class II molecules according to the culture conditions. In order to detect DC exposing $\mathrm{MHC}$ class II molecules at the cell surface, immunofluorescence labeling was performed without pretreatment by a detergent for membrane permeabilization. Qualitative and quantitative data are presented in Figures 7 and 8. Freshly isolated DC presented MHC class II molecules at the cell surface and numbering of $\mathrm{MHC}$ class IIpositive cells, with or without membrane permeabilization, yielded similar values. The same observations were made for all time points over the 8-day period of culture 


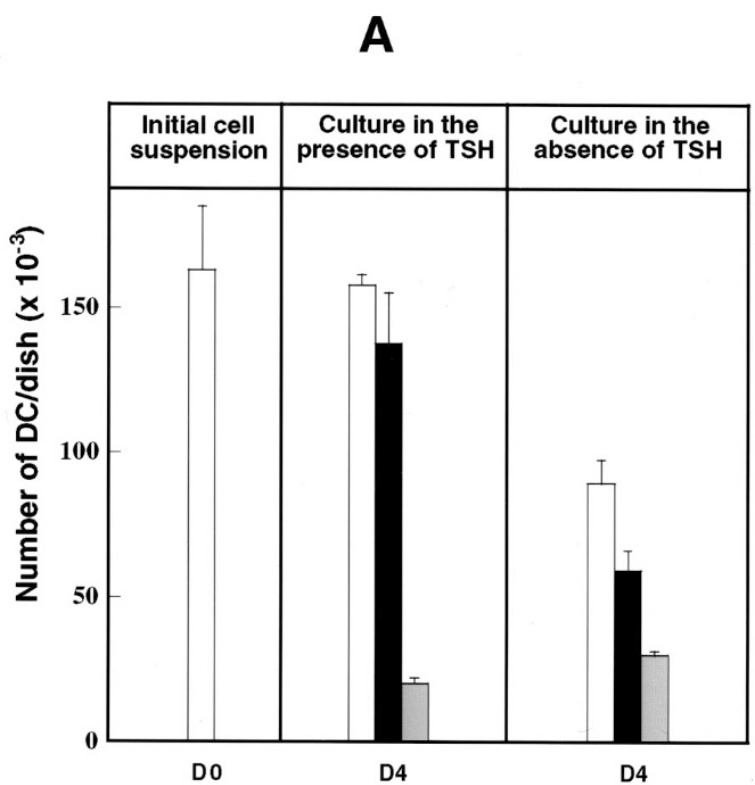

B
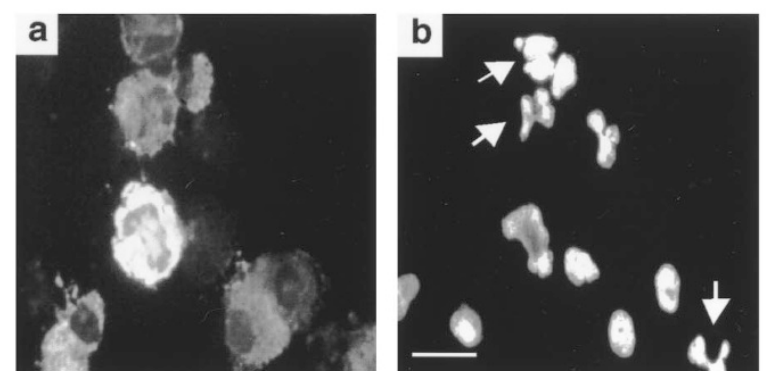

Figure 4.

A, DC exhibit an increased propensity to detach from the culture substratum when cocultured with thyrocytes in the absence of TSH. Freshly isolated cells (ie, thyrocytes) and DC (DO) were either spread on glass slides by cytocentrifugation for subsequent analyses or seeded at a density of $0.5 \times 10^{6}$ cells $/ \mathrm{cm}^{2}$ and cultured for 4 days in the absence or in the presence of $1 \mathrm{mU} / \mathrm{ml}$ TSH. At Day 4, adherent cells and cells present in the culture medium (ie, floating cells) collected by cytocentrifugation were either used for DNA assay or processed for MHC class II immunolabeling. MHC class II-positive cells and Hoechst-labeled nuclei were counted on 10 microscope fields per dish or cytocentrifugation slide. Values were used to determine the proportion of DC (MHC class II-positive cells) in percent of the total cell population. The total number of DC (open columns), the number of DC attached to the culture dish (black columns), and the number of floating DC (gray columns) were calculated by multiplying the proportion of DC in each cell fraction by the total number of cells present in the fraction estimated by DNA assay. Results are the mean \pm SEM of triplicate. B, Morphological examination of cells that detach from the culture dish. MHC class II immunolabeling (a) and Hoechst reagent labeling (b) of cells collected by cytocentrifugation from the medium after 4 days of culture in the absence of TSH. Note that some MHC class II-positive cells exhibited a fragmented nucleus (arrows). Bar: $10 \mu \mathrm{m}$.

in the presence of TSH (Fig. 7A). The observed ratios between the number of labeled DC without permeabilization and the number of labeled DC with permeabilization were, most of the time, slightly higher but not statistically different from $100 \%$. This was probably due to the loss (detachment) of some DC at the detergenttreatment step. Unexpectedly, when DC were cultured in the absence of $\mathrm{TSH}$, the MHC class II distribution was rapidly altered. After 2 days, the proportion of DC exhib-

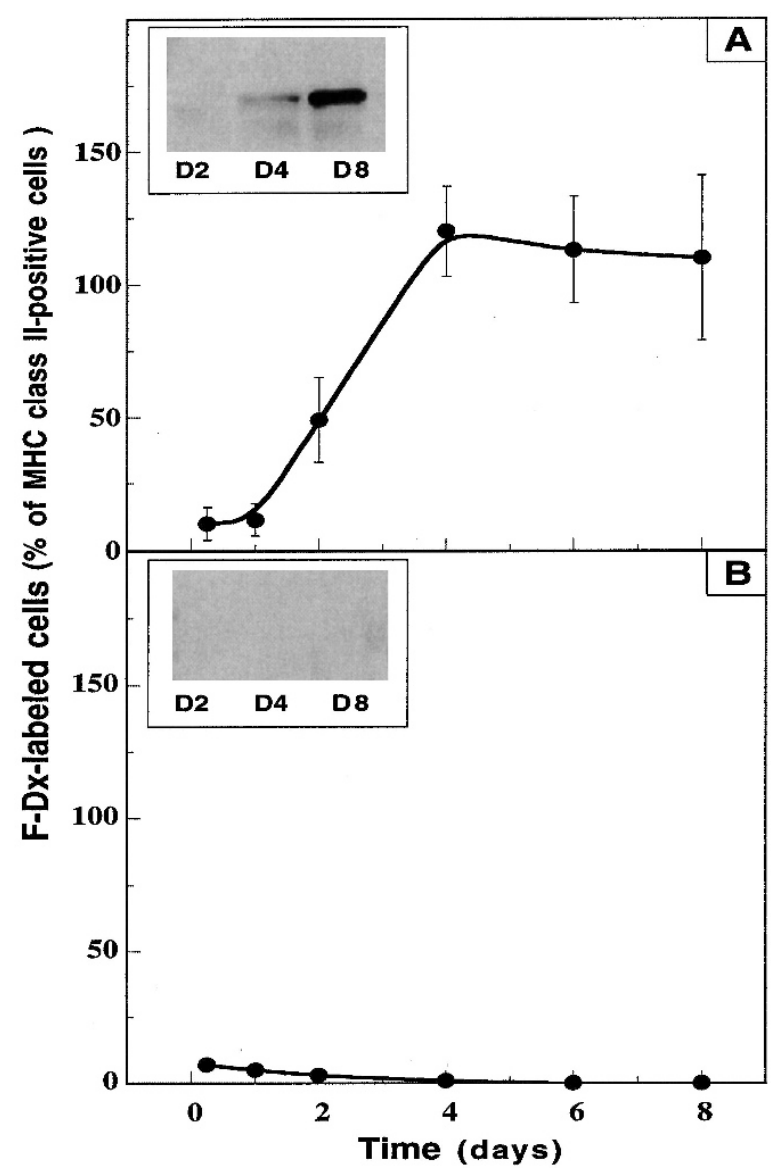

Figure 5.

Changes in the capacity of endocytosis and mannose receptor expression of $D C$ cocultured with thyrocytes over an 8-day period in the presence $(A)$ or in the absence $(\mathrm{B})$ of TSH. Culture conditions were the same as those described in the legend of Figure 2. At the indicated times, cells were incubated with F-Dx for 3 hours at $37^{\circ} \mathrm{C}$ and then fixed and processed for MHC class II immunodetection. F-Dx-labeled cells and MHC class II-labeled cells were counted on 10 microscope fields per dish and values were used to calculate the percentage of F-Dx-labeled cells within the MHC class II-positive cell population. Results are the mean \pm SEM of measurements from 4 dishes in a representative experiment. At Days 2, 4, and 8, membrane fractions were prepared from cell lysates and used to detect the mannose receptor by western blot. Results are presented as inserts (A and B).

iting $\mathrm{MHC}$ class II molecules at the cell surface was close to or equal to zero (Fig. 7B). The immunofluorescence images of Figure 8 show the MHC class II labeling of freshly isolated DC (panel A) and DC cultured for 4 days with TSH (panel B), with and without detergent treatment. There was a complete lack of MHC class II at the cell surface of DC (immunolabeling without detergent treatment) when cells were cultured for 4 days in the absence of TSH (panel C).

\section{In Response to TSH, Thyrocytes Produce Soluble Factors Regulating the Number of and Endocytic Activity of DC}

The data mentioned above show that addition of TSH to DC/thyrocyte cocultures altered DC properties. To determine whether TSH was acting directly on DC (through potential TSH receptors) (Bagriacik and Klein, 2000), or indirectly through soluble factors produced by thyrocytes, we prepared enriched populations of 

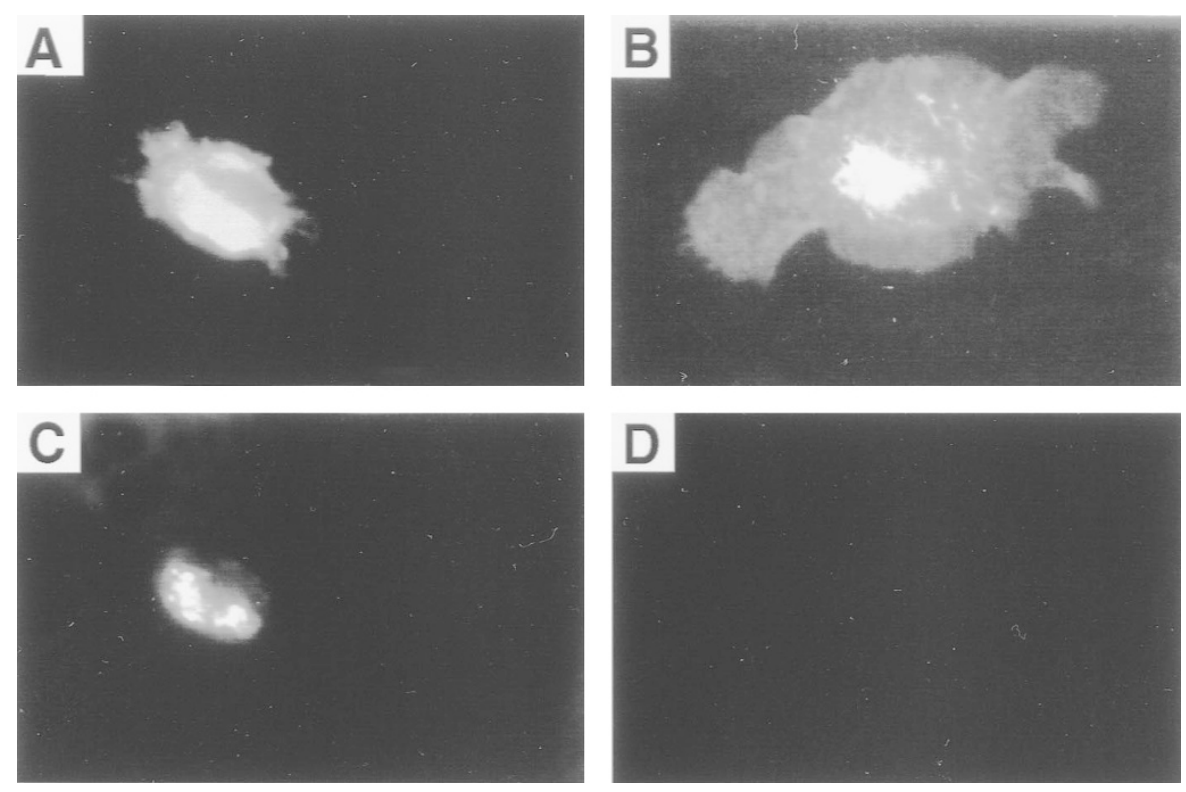

Figure 6.

Evidence that DC cocultured with thyrocytes in the absence of TSH were devoid of endocytic activity. Cells cultured with (A, C) or without (B, D) TSH for 4 days were incubated with F-Dx for 3 hours at $37^{\circ} \mathrm{C}$ and then fixed and processed for MHC class II immunodetection. A and B, MHC class II labeling; C and D, Internalization of F-Dx. Bar: $10 \mu \mathrm{m}$.

thyroid-derived DC. The approach used was based on microscope observations suggesting that $\mathrm{DC}$ could be more adherent to the culture substratum than thyrocytes engaged in the formation of follicle structures. Thus, we used a mild treatment by a trypsin-EDTA solution to try to obtain a preferential elimination of thyrocytes from the DC/thyrocyte cocultures. The results of two experiments are reported in Table 1. It can be seen that the trypsin-EDTA treatment led to the removal of more than $99 \%$ of cells, but the remaining adherent cell populations were composed of $15 \%$ to $30 \%$ of DC. The $60 \mathrm{~mm}$ culture dish contained a sufficient number of DC to perform quantitative studies and an extremely low number of thyrocytes. These enriched-DC preparations were used to investigate whether TSH could directly activate DC and whether conditioned media (ie, culture medium supernatants deriving from DC/thyrocyte cocultures) contained active factors capable of increasing the number and endocytic activity of DC. Enriched DC preparations were cultured for 3 days in either fresh standard medium, in the absence of or in the presence of TSH, or conditioned medium deriving from DC/thyrocytes cocultured for 24 or 72 hours with TSH or 72 hours without TSH. Results of a representative experiment out of three are summarized in Figure 9. Culture in standard medium, irrespective of the presence or absence of TSH, led to a $60 \%$ to $70 \%$ decrease in the DC population. This result shows that TSH did not directly activate DC. On the contrary, conditioned media resulting from 72 hours of coculture of DC and thyrocytes with TSH induced a 2- to 3-fold increase in the number of MHC class II-positive cells and the number of F-Dx-labeled cells. Conditioned media resulting from 24 hours of DC/thyrocyte coculture with TSH exerted a weak but significant effect. The ab- sence of effect of the conditioned media resulting from 72 hours of coculture without TSH show the specificity of the observed effects with the conditioned media endowed with a regulatory activity. Irrespective of the experimental conditions and the changes in the number of DC, the residual thyrocyte population was multiplied by two to three. This result was expected, because pig thyrocytes at a low or very low cell density, as was the case here, are able to go through two to three cell cycles (unpublished data). These data show that conditioned media contained soluble factors endowed with regulatory activities on DC, ie, activation of proliferation and endocytic activity.

Three growth factors or cytokines were tested for their ability to reproduce the effects of conditioned media. DC/thyrocytes were cocultured for 1 day in complete medium to allow cell attachment to the substratum and further cultured for 3 days in serumfree medium with or without either TSH (positive control) or granulocyte/macrophage-colony stimulating factor (GM-CSF) or transforming growth factor- $\beta 1$ (TGF $\beta 1$ ) or vascular endothelial growth factor (VEGF). Results are reported in Figure 10. GM-CSF and TGF $\beta 1$, at concentrations eliciting maximal responses on different in vitro cell systems, were as efficient as $\mathrm{TSH}$ to increase the number and the endocytic activity of MHC class II-positive cells. By contrast, VEGF was devoid of any activity.

\section{Discussion}

We report that $\mathrm{TSH}$, the main regulatory signal for thyroid cell growth and differentiation (Dumont et al, 1992), exerts a control on the fate and functional state of thyroid-derived DC cocultured with thyrocytes (in a proportion reflecting the in situ DC/thyrocytes ratio). 


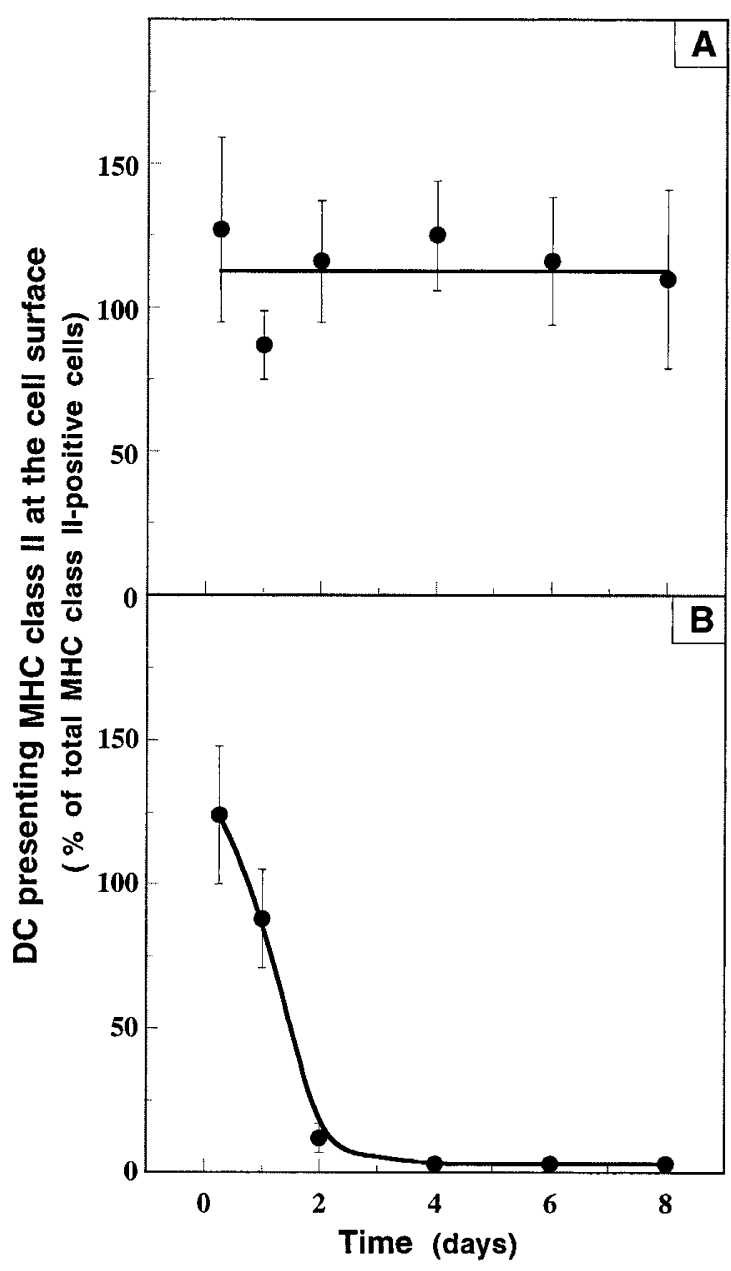

Figure 7.

Changes in the subcellular location of MHC class II molecules expressed by DC cocultured with thyrocytes in the presence $(A)$ or in the absence $(B)$ of TSH over an 8-day period. Culture conditions were the same as those described in the legend of Figure 2. At the indicated times, immunolabeling of MHC class II molecules was performed with or without cell permeabilization in PBS containing $0.5 \%$ saponin. MHC class II-positive cells were counted as described in the legend of Figure 2, and values were used to calculate the proportion of DC expressing MHC class II molecules at the plasma membrane in percent of total MHC class II-positive cells. Results are the mean \pm SEM of measurements from 4 dishes.

TSH appears to be required for the survival of DC, to induce DC multiplication, and to promote a differentiated function of DC (ie, endocytosis). The regulatory actions of $\mathrm{TSH}$ on thyroid-derived $\mathrm{DC}$ require the presence of thyrocytes. Indeed, thyrocyte-depleted, enriched populations of DC were no longer capable of responding to $\mathrm{TSH}$. The fact that conditioned media from TSH-treated thyrocytes reproduced the effects of TSH on DC/thyrocytes cocultures gives evidence for an indirect communication process related to the production, by TSH-activated thyrocytes, of soluble factors acting on DC and modulating their proliferation and functional activity. In light of the recent report showing that DC prepared from spleen and lymph nodes express TSH receptors (Bagriacik and Klein, 2000), one might consider that the response of thyroid-derived DC, either cocultured with TSHtreated thyrocytes or cultured with conditioned media from TSH-treated thyrocytes, could bring into play TSH receptors expressed by DC. DC alone would not express TSH receptors, but soluble factors produced by TSH-activated thyrocytes could trigger the expression of TSH receptors by DC and, thus, allow their response to $\mathrm{TSH}$. In this hypothesis, the phenotypic changes of DC would depend on TSH receptor expression and, thus, TSH actions on both thyrocytes and DC. Checking this hypothesis seems extremely difficult, because it would require the obtention of DC populations free from thyrocytes to analyze their actual capacity for expressing TSH receptors.

Signaling from epithelial cells to DC has already been described in vitro with skin- and lung-derived cells. It is well established that keratinocytes in coculture with epidermal DC or Langerhans cells produce factors that condition the survival and activity of DC (Heufler et al, 1988). Similarly, alveolar epithelial cells in coculture with pulmonary DC modify the functional activity of DC (Christensen et al, 1995). In addition, our data show that thyroid epithelial cells/DC interactions can be regulated by $\mathrm{TSH}$, a hormone that controls epithelial cell functions. If the factors involved in previously described epithelial cells/DC interactions had not been fully identified, the recent intense research on DC has provided a rather long list of candidate signaling molecules that regulate all the different aspects of the life and function of DC. From literature data, we looked for cytokines or growth factors, acting as regulators of DC survival and/or multiplication and/or maturation, that are produced by thyrocytes. Three factors emerged: GMCSF, TGF $\beta$, and VEGF.

GM-CSF is a determining factor for the in vitro survival and development of epidermal DC and is widely used to generate DC from blood or bone marrow progenitor cells (Heufler et al, 1988; Inaba et al, 1992; Sallusto and Lanzavecchia, 1994). It has been reported that GM-CSF is produced by human thyroid cell lines (Aust et al, 1996) and by normal human thyrocytes and thyrocytes from patients with Graves' disease (Kasai et al, 1997).

TGF $\beta$ exerts broad effects on DC; it is particularly capable of inhibiting maturation of both epidermal (Yamaguchi et al, 1997) and bone marrow-derived DC (Strobl and Knapp, 1999; Yamaguchi, 1998) and protects DC from apoptosis (Riedl et al, 1997). Thyrocytes from different species produce high amounts of TGF $\beta$ in response to TSH (Contempre et al, 1996; Kolaja and Klaassen, 1998; Morosini et al, 1996; Pekary et al, 1995; Roger, 1996).

VEGF, unlike GM-CSF and TGF $\beta$, has been shown to inhibit the development of DC from hematopoietic progenitors (Gabrilovich et al, 1996, 1998, 1999). VEGF is secreted by normal and tumoral thyrocytes and its production is stimulated by TSH (Sato et al, 1995; Soh et al, 1996; Viglietto et al, 1997; Wang et al, 1998).

When added to DC/thyrocytes cocultures, GM-CSF and TGF $\beta$ reproduced the effects of conditioned media but, as expected from its known actions on DC, VEGF did not promote any increase in thyroid-derived DC number or function. Thus GM-CSF and TGF $\beta$ seem, by themselves, fully capable of mediating the 

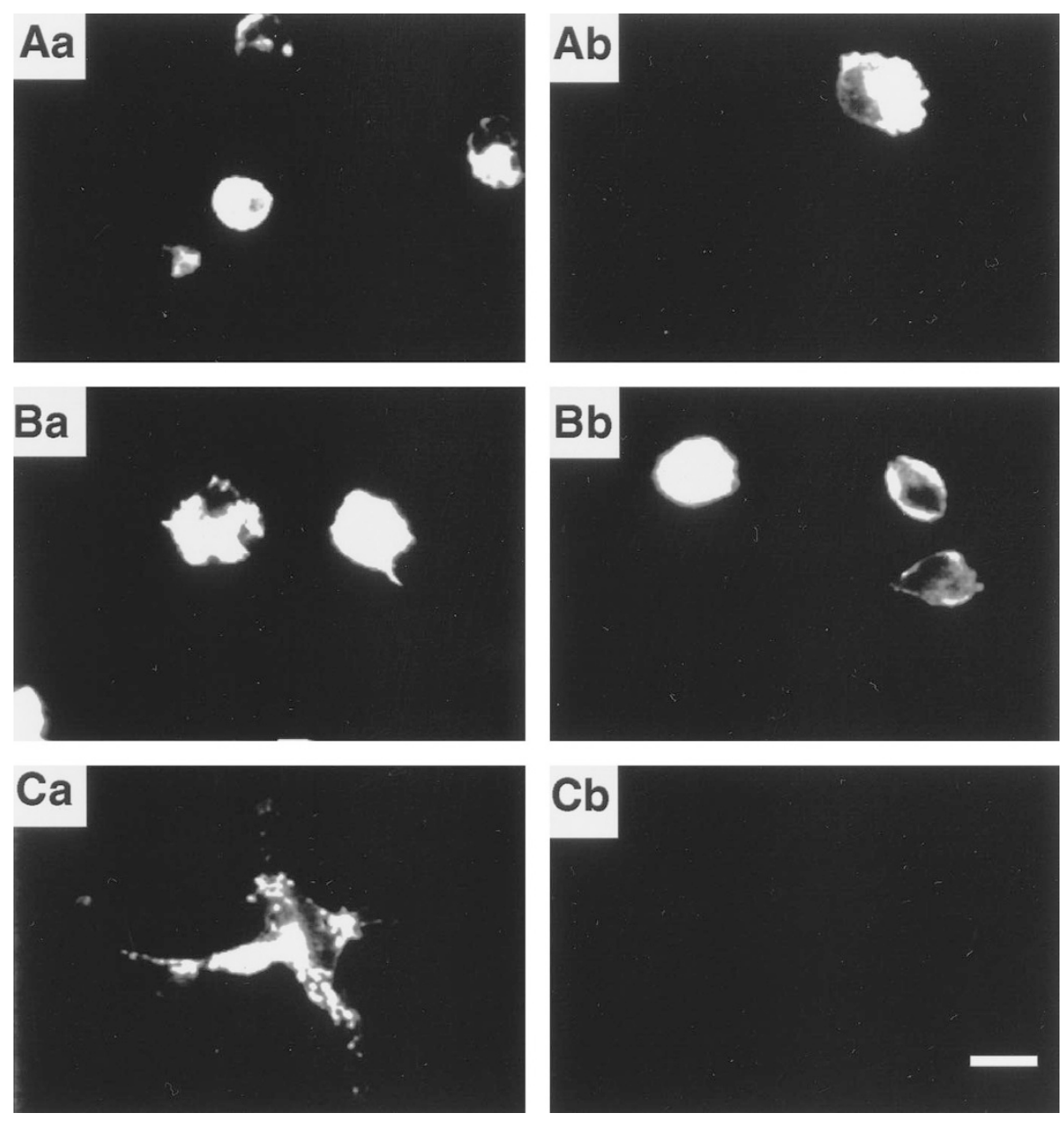

Figure 8.

Evidence that DC cocultured with thyrocytes in the absence of TSH no longer express MHC class II molecules at the cell surface. Freshly isolated cells spread on glass slides by cytocentrifugation (A) and cells cultured for 4 days with (B) or without (C) TSH were fixed and processed for MHC class II immunolabeling with (Aa to $\mathrm{Ca}$ ) or without ( $\mathrm{Ab}$ to $\mathrm{Cb}$ ) pretreatment with $0.5 \%$ saponin for membrane permeabilization. Bar: $15 \mu \mathrm{m}$.

Table 1. Preparation of Enriched Populations of DC from DC/Thyrocytes Cocultures

\begin{tabular}{|c|c|c|c|c|c|}
\hline Exp & $\begin{array}{c}\text { Cell } \\
\text { treatment }\end{array}$ & $\begin{array}{c}\text { Total cell } \\
\text { number/dish }\end{array}$ & $\begin{array}{l}\text { MHC class } \\
\text { II-positive } \\
\text { cells/dish }\end{array}$ & $\begin{array}{c}\text { Percent } \\
\text { DC }\end{array}$ & $\begin{array}{c}\text { DC } \\
\text { enrichment }\end{array}$ \\
\hline \multirow{2}{*}{1} & None & $7.8 \pm 0.7 \times 10^{6}$ & $82,400 \pm 7,600$ & $1.0 \pm 0.1$ & 一 \\
\hline & Trypsin-EDTA & $18,000 \pm 3,600$ & $2,650 \pm 30$ & $14.7 \pm 1.6$ & 14.7 \\
\hline \multirow{2}{*}{2} & None & $5.8 \pm 0.24 \times 10^{6}$ & $177,300 \pm 7,400$ & $3.0 \pm 0.1$ & - \\
\hline & Trypsin-EDTA & $26,200 \pm 1,200$ & $8,600 \pm 560$ & $32.6 \pm 2.1$ & 10.8 \\
\hline
\end{tabular}

DC, dendritic cells; TSH, thyrotropin. Freshly isolated cells were cultured for 4 days in the presence of $1 \mathrm{mU} / \mathrm{ml}$ TSH. At day 4 , adherent cells were subjected to a 5-minute treatment by a $0.25 \%$ trypsin- $0.5 \mathrm{mM}$ EDTA solution and vigorously washed by fluid sprinkling over the cell layer. Untreated cells (total cell population) and adherent cells recovered after trypsin-EDTA treatment and fixed and processed for MHC class II immunolabeling. Nuclei were labeled using the Hoechst 33342 reagent. Hoechst-labeled nuclei and MHC class II-positive cells were counted on 40 microscope fields using the $\times 40$ objective in 2 to 3 dishes. Values were used to determine the total number of cells (thyrocytes and DC) and the total number of DC per dish, knowing the area of the microscope field and the total number of fields per dish. Results represent the mean \pm SEM.

communication from thyrocytes to $\mathrm{DC}$ in response to TSH. Because of the lack of validated reagents in the porcine species, we were not able to assay these cytokines in culture media. If produced in low amounts as compared with those required to obtain the full response, GM-CSF, TGF $\beta$, (and possibly other factors) might exert conjugated actions accounting for the thyrocyte-mediated, TSH-induced effects on DC. Cooperation between various cytokines might happen not only at the level of DC but also at the level of thyrocytes. 


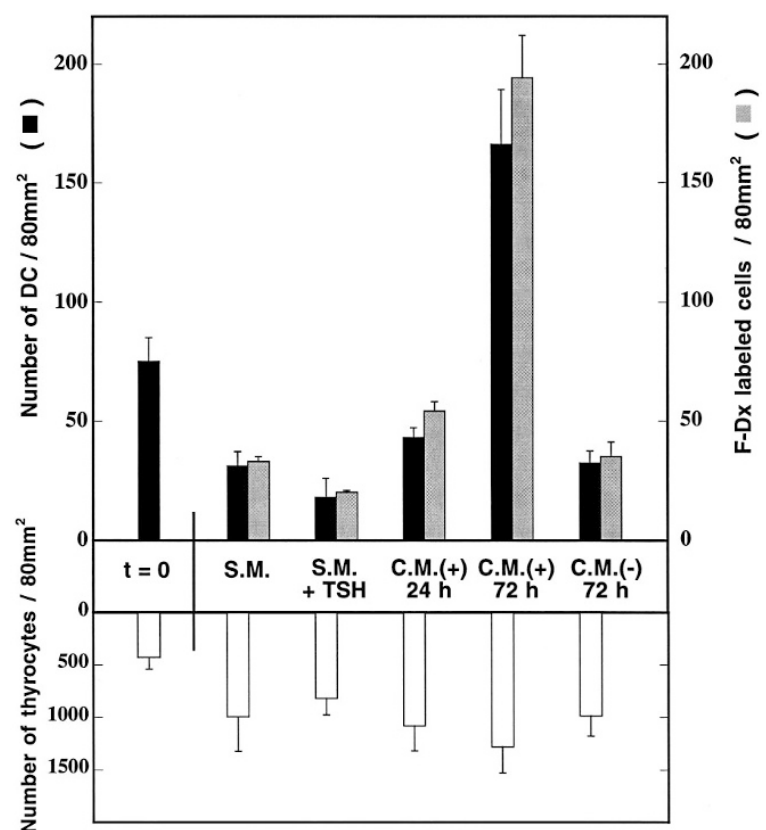

Figure 9.

Demonstration that, in response to TSH, thyrocytes produce soluble factors acting on DC proliferation and differentiation. Freshly isolated cells were cultured for 4 days in the presence of TSH and subjected to a 5-minute treatment with a trypsin-EDTA solution. Cells that remained adherent (enriched DC population) were further cultured for 3 days in fresh Ham's F12 standard medium (S.M.), with or without TSH, or conditioned media (C.M.). Conditioned media corresponded to culture media of thyrocytes and DC cultured for 24 or 72 hours with TSH $(\mathrm{CM}+)$ or for 72 hours without TSH $(\mathrm{CM}-)$. At the outset $(\mathrm{t}=0)$ and at the end of the 3-day culture period, cells were incubated with F-Dx for 3 hours at $37^{\circ} \mathrm{C}$ and then fixed and processed for MHC class II immunolabeling. Finally, nuclei were labeled by the Hoechst 33342 reagent. MHC class II-positive cells (black columns), F-Dx-labeled cells (gray columns), and Hoechst-labeled nuclei were counted in 4 microscope fields of $20 \mathrm{~mm}^{2}$. The number of thyrocytes (open columns) was obtained as the difference between the number of Hoechst-labeled nuclei (total cell number) and the number of MHC class II-labeled cells (DC). Columns and vertical bars represent the mean and SEM of values obtained from 4 separate dishes in a representative experiment (out of 3 ).

Indeed, TGF $\beta$ produced in response to TSH stimulation of thyrocytes might activate, via an autocrine loop, the production of GM-CSF by thyrocytes (Matsumura et al, 1999). The same could apply for other factors participating in thyrocytes-DC interactions.

Thyroid-derived DC maintained in culture for up to 8 days, thanks to the presence of thyrocytes and TSH were classified as immature DC; they show both similarities and differences with immature DC from another origin. Like other immature DC, thyroidderived DC had a high endocytic activity, expressed the mannose receptor and MHC class II molecules, and remained adherent to the culture substratum. At variance with epidermal DC and DC generated from progenitors that maintain MHC class II molecules in intracellular compartments for peptide loading, immature DC coming from the thyroid gland expose $\mathrm{MHC}$ class II at the cell surface. Recent findings from Santambrogio et al (1999a, 1999b) offer an explanation for this discrepancy. These authors found that splenic or bone marrow-derived DC in an immature state express empty MHC class II molecules at the cell surface. These membrane proteins would bind peptides processed by proteases outside the cells. This additional mechanism of antigen presentation to $\mathrm{T}$ cells without intracellular processing, consistent with the role of DC as sentinels, might be operational in the thyroid gland.

The maturational stage of thyroid-derived DC cultured in the absence of TSH was more difficult to define. Indeed, the intracellular location of MHC class II molecules would suggest an immature phenotype, whereas the lack of endocytic activity is a characteristic of mature DC. In the absence of TSH, thyroid-derived DC may simply be in the process of apoptosing and are therefore not of any known maturational stage.

Signaling between epithelial and dendritic cells might be bidirectional. It has indeed been reported that DC might exert a control on growth and functional activity of endocrine cells. In the pituitary gland, DC, known as folliculostellate cells, produce cytokines such as IFN $\gamma$ or IL-6 that inhibit ACTH and gonadotrophin release (Allaerts et al, 1994; Baes et al, 1987; Hoek et al, 1997). Regulatory actions of DC on thyroid epithelial cells have also been described using DC extracted from rat spleen and rat thyrocytes in coculture (Simons et al, 1998). DC via the production of IL-1 $\beta$ and IL-6 were found to substantially inhibit thyroid cell proliferation and to decrease, though to a lesser extent, thyroid hormone release.

The reciprocal interactions or crosstalk between DC and thyrocytes, although still little is known, might be of importance in the first stages of thyroid autoimmune processes. Until recently, it was admitted that the triggering factor of autoimmunity was the abnormal expression of MHC class II molecules by thyrocytes (Bottazzo et al, 1983; Hanafusa et al, 1983). During the recent years, a new mechanism was proposed; it assigns a central role to antigen-presenting cells, especially DC. Autoimmunity could be primed by DC after their differentiation by certain cytokines (Drakesmith et al, 2000). The first sign of the development of an autoimmune process is often the accumulation of DC within the gland, which is observed before the appearance of antibodies directed against thyroid autoantigens: thyroglobulin, thyroid peroxidase, or the TSH receptor, and before the appearance of autoreactive $T$ lymphocytes. The intrathyroidal accumulation of DC has been found in different animal models: diabetes-prone BB-DP rats, nonobese diabetic NOD mice, and obese strain chicken (Hala et al, 1996; Many et al, 1995; Voorby et al, 1990), and in patients with thyroid autoimmune diseases (Kabel et al, 1988). Signals attracting or favoring the accumulation of DC within the thyroid gland could originate from thyrocytes (Mooij et al, 1994). Our data suggest that the accumulation of DC could also result from in situ DC proliferation triggered by signals coming from thyrocytes.

In conclusion, thanks to the use of pig thyroid glands that are available and workable in much larger amounts than either human, mouse, or rat thyroids, we have generated data on intrathyroidal DC (in terms of preparation, culture, characterization, and functional activity) that should be helpful for the development of 


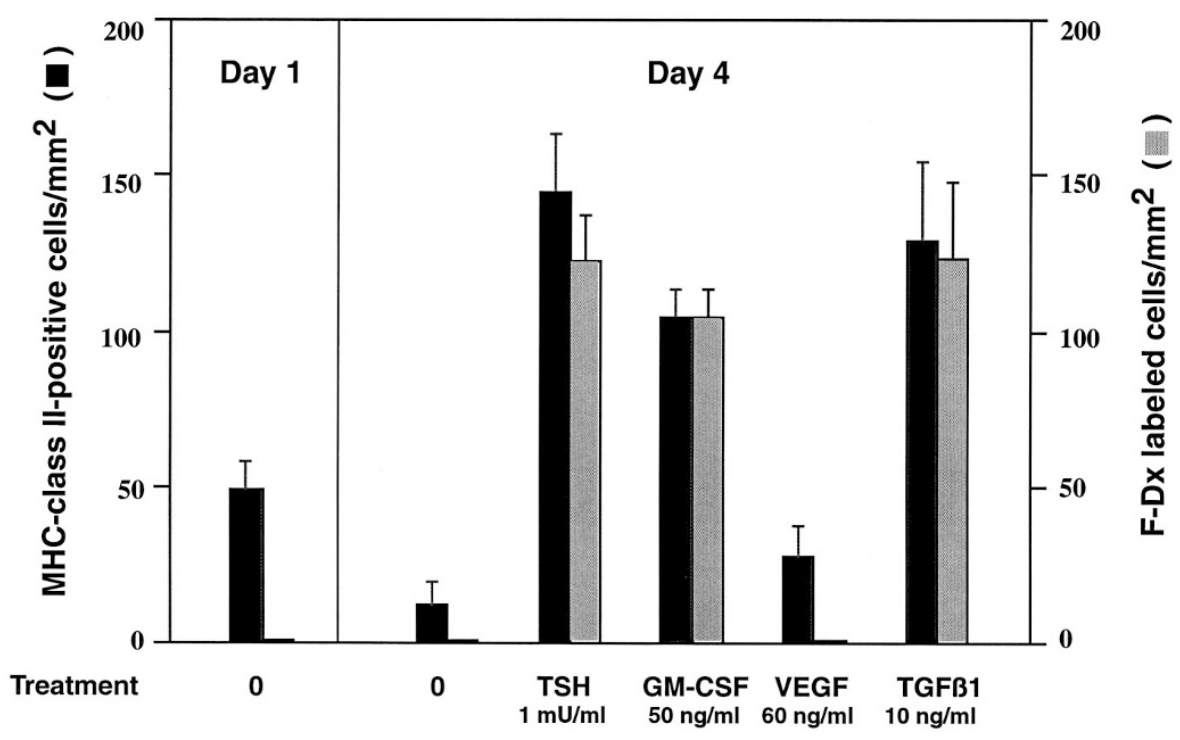

Figure 10.

Granulocyte/macrophage-colony stimulating factor (GM-CSF) and transforming growth factor- $\beta 1$ (TGF $\beta 1$ ) induce an increase in the number and endocytic activity of thyroid-derived DC. Freshly isolated cells (thyrocytes and DC) were cultured in the complete medium for 24 hours then in serum free medium alone or supplemented with either TSH, GM-CSF, vascular endothelial growth factor (VEGF), or TGF $\beta 1$ for 3 days. At Day 1 ( $t=0)$ and Day 4 , cells were incubated with F-Dx for 3 hours at $37^{\circ} \mathrm{C}$ and then fixed and processed for MHC class II immunolabeling. MHC class II-positive cells (black columns) and F-Dx labeled cells (gray columns) were counted on 5 microscope fields per dish. Values were used to calculate the number of labeled cells per $\mathrm{mm}^{2}$. Columns and vertical bars are the mean and sem of the values from 4 dishes.

a smaller scale culture of thyroid-derived DC from human tissue and mouse or rat experimental models. Analyses of the immunological functions of thyroidderived DC with these culture systems will probably contribute to the definition of the role of intrathyroidal $\mathrm{DC}$ in the triggering and progression of autoimmunity.

\section{Materials and Methods}

\section{Materials}

Ham's F12 medium and RPMI 1640 medium without L-glutamine were obtained from Seromed (Biochrom KG, Berlin, Germany). Porcine trypsin was purchased from GibcoBRL (Paisley, United Kingdom). Bovine TSH (2 U/mg), F-Dx (MM: 40,000 Da), the mouse monoclonal anti-bovine $\mathrm{S} 100 \beta$ antibody, and goat anti-mouse IgG conjugated to peroxidase were obtained from Sigma Chemical (St. Louis, Missouri). The monoclonal antibody (15-2-2) directed against the human mannose receptor was a gift from Dr. D. C. Rijken, Gaubius laboratory, Leiden, The Netherlands. The anti-MHC class II antibody was a monoclonal anti-human HLA class II (DR) antibody obtained from Novocastra (Newcastle, United Kingdom). 5-bromo-2'deoxyuridine (BrdU) was obtained from Amersham (Buckinghamshire, United Kingdom). The monoclonal antibody directed against BrdU was purchased from ICN (Aurora, Ohio). Goat anti-mouse IgG, F(ab') specific antibodies conjugated to either Texas Red or FITC were obtained from Jackson Immunoresearch (West Grove, Pennsylvania). The Hoechst 33342 reagent was purchased from Molecular Probes (Leiden, The Netherlands). Immobilon-P membranes were obtained from Millipore (Bedford, Massachusetts). The ECL kit was obtained from Covalab (Lyon, France). Recombi- nant human GM-CSF and recombinant human VEGF ${ }_{165}$ were obtained from Tebu (Le Perray-en-Yvelines, France) and Oncogene Science (Cambridge, Massachusetts), respectively. Porcine TGF $\beta 1$ was from R \& D Systems Europe (Oxford, United Kingdom).

\section{Isolation and Coculture of Thyrocytes and DC}

Thyrocytes and DC were isolated from pig thyroid glands by discontinuous trypsin treatment as previously reported (Croizet et al, 2000). The resulting cell suspension contained thyrocytes and $2 \%$ to $3 \%$ of DC identified as MHC class II and S100-positive cells (Banchereau and Steinman, 1998; Caux et al, 1996; Steinman, 1991). Cells were suspended in Ham's F12 medium supplemented with penicillin (100 U/ml), streptomycin $(0.1 \mathrm{mg} / \mathrm{ml})$, amphotericin B $(0.25 \mu \mathrm{g} /$ $\mathrm{ml})$, and $5 \%$ calf serum and seeded in $60-\mathrm{mm}$ culture dishes at a density of $0.5 \times 10^{6} \mathrm{cells} / \mathrm{cm}^{2}$. TSH ( 1 $\mathrm{mU} / \mathrm{ml}$ ) was added or not to the culture medium from Day 0. After one day of culture, the medium was changed and replaced by the same, but serum-free, medium. Cells were maintained in culture for up to 8 days at $37^{\circ} \mathrm{C}$ in air $/ \mathrm{CO}_{2}(95 / 5 \%)$ atmosphere. Thyroid cells, cultured in the presence of TSH, were reorganized into histiotypic structures named reconstituted thyroid follicles. Thyrocytes cultured in the absence of TSH formed a cell monolayer.

\section{Collection of Cells in Suspension}

Freshly isolated cells (thyrocytes and dendritic cells) and cells present in culture media (floating cells) were pelleted by centrifugation at $400 \times g$ for 10 minutes, resuspended in 100 to $300 \mu$ l undiluted calf serum, 
and spread on glass slides by cytocentrifugation at 50 $\times g$ for 10 minutes using a cytospin centrifuge from Shandon Elliott (Camberley, United Kingdom). Cells on glass slides were submitted to the same fixation and labeling protocols as those used for adherent cells.

\section{Endocytosis of Fluorescent Ligands}

Cells were incubated with F-Dx $(1 \mathrm{mg} / \mathrm{ml})$ for 3 hours at $37^{\circ} \mathrm{C}$. At the end of the incubation period, culture media were collected and adherent cells were washed three times with cold Earle's medium, $\mathrm{pH} 7$, and fixed for 30 minutes at room temperature in $4 \%$ paraformaldehyde in PBS for delayed quantitative fluorescence microscope analyses and subsequent immunodetection of MHC class II.

\section{Immunolabeling Procedures}

Cells were fixed either in $70 \%$ cold ethanol for 30 minutes at $4^{\circ} \mathrm{C}$ for mannose receptor immunodetection or in $4 \%$ paraformaldehyde in PBS for 30 minutes at room temperature for MHC class II and S100 immunolabelings. Paraformaldehyde fixed-cells were then permeabilized or not in $0.05 \%$ Tween 20 (S100 immunolabeling) or $0.5 \%$ saponin (MHC class II detection) in PBS for 30 minutes at room temperature. After a 1 hour-preincubation at room temperature in PBS containing $10 \mathrm{mg} / \mathrm{ml}$ BSA (PBS-BSA), cells were incubated with either the mouse anti-HLA class II (DR) (final dilution $1 / 200$ ), the monoclonal antibody directed against the mannose receptor $(1 \mu \mathrm{g} / \mathrm{ml})$, or the mouse anti-S100 $\beta$ (final dilution 1/500) for 1 hour at $37^{\circ} \mathrm{C}$. After extensive washings, immune complexes were detected with goat anti-mouse $\operatorname{lgG}, F\left(a b^{\prime}\right)_{2}$, specific antibodies conjugated to either Texas Red or FITC. Nuclei staining was obtained by incubating cells with 2 $\mu \mathrm{g} / \mathrm{ml}$ Hoechst 33342 reagent for 15 minutes at room temperature.

\section{Videomicroscope Fluorescence Image Processing and Quantitative Analyses}

Fluorescence images, obtained with a Zeiss Axiophot fluorescence microscope equipped with the following filter combinations (excitation-emission): G 365 LP 420 for Hoechst, BP 615 LP 590 for Texas Red, and BP 450-490 LP 520 for FITC, were monitored using a cooled CCD camera (Lhesa electronique, Cergy Pontoise, France). Images were transferred on a 80486 based IBM compatible personal computer equipped with a Cyclope imaging card (Digital Vision, Chatillon, France). Softwares were designed for image-noise reduction. In the case of double or triple labeling with fluorescein and/or Texas red and Hoechst reagent, fluorescence images corresponding to each fluorophore were recorded sequentially. Images, converted as TIFF files, were treated with Adobe Photoshop (Adobe Systems, Mountain View, California). Quantitative analyses of cells labeled by endocytosis of F-Dx or immunolabeled with a given antibody were performed on 10 or 20 microscope fields taken at random in each culture dish using the $\times 63$ objective. Numbering of labeled cells and Hoechst-labeled nuclei (giving the total number of cells) in a given field was carried out by manual counting on a monitor screen. Values were used to calculate the average number of labeled cells per $\mathrm{mm}^{2}$ and/or the proportion of labeled cells (in percent of total cells) in the culture dish. Measurements were made on duplicate or triplicate dishes.

\section{SDS - PAGE and Western Blot}

Thyroid cells were collected by scraping in PBS pH 7.4 containing EDTA (5 mM), PMSF (1 $\mathrm{mm})$, and protease inhibitors: aprotinin, leupeptin, and pepstatin (each at a concentration of $1 \mu \mathrm{g} / \mathrm{ml}$ ) and were lysed by freezing-thawing. Cell homogenates were centrifuged at $100,000 \times g$ for 30 minutes at $4^{\circ} \mathrm{C}$ to obtain membrane fractions. Proteins were assayed according to the Lowry method after solubilization in $0.1 \%$ deoxycholate. Protein samples $(80 \mu \mathrm{g})$ from membrane fractions were separated by SDS-PAGE on $6 \%$ acrylamide slab minigels and then transferred onto Immobilon-P membranes. Membranes were preincu-

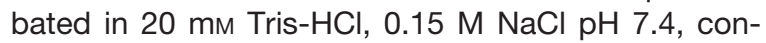
taining $5 \mathrm{~mm}$ EDTA, $0.5 \%$ Tween 20 , and $1 \mathrm{mg} / \mathrm{ml} \mathrm{BSA}$ for 1 hour at room temperature and then incubated with the monoclonal anti-mannose receptor antibody $(0.1 \mu \mathrm{g} / \mathrm{ml})$ for 2 hours at room temperature. Detection of immune complexes was performed using horseradish peroxidase-conjugated goat anti-mouse Ig antibodies. After 1 hour at room temperature, horseradish peroxidase activity was detected using an enhanced chemiluminescence detection procedure (ECL kit) and exposure to Kodak X-Omat AR film (Eastman Kodak, Rochester, New York)

\section{Cell Proliferation Analysis}

Cells undergoing division were detected by 5 -bromo2 'deoxyuridine (BrdU) incorporation into DNA. Cells incubated for 6 hours in the presence of $3 \mu \mathrm{g} / \mathrm{ml} \mathrm{BrdU}$ in RPMI 1640 medium without L-glutamate, were fixed in $70 \%$ ethanol (precooled at $-20^{\circ} \mathrm{C}$ ) for 30 minutes at $4^{\circ} \mathrm{C}$ and subjected to a 10 -minute treatment in $2 \mathrm{~N}$ $\mathrm{HCl}$ at $37^{\circ} \mathrm{C}$. After extensive washing in $0.1 \mathrm{M}$ borate, $\mathrm{pH}$ 8.5, cells were incubated for 1 hour at room temperature with an anti-BrdU mouse monoclonal antibody. Immune complexes were visualized using the secondary antibody mentioned above.

\section{Other Methods}

For DNA assay, cells were scraped from the dishes in $100 \mathrm{~mm}$ Tris, $10 \mathrm{~mm}$ EDTA, and $3 \mathrm{M} \mathrm{NaCl}, \mathrm{pH} 7.4$ and were lysed by sonication for 20 seconds at 25 watts using the vibra-cell apparatus (Bioblock Scientific, Illkirch, France). DNA assay was performed with the fluorometric method of Labarca and Paigen (1980) using the Hoechst 33258 reagent and calf thymus DNA as standard. Cell number was deduced from DNA measurements considering that $10^{6}$ cells contain $10 \mu \mathrm{g}$ of DNA. 


\section{Acknowledgements}

We thank Dr. D. C. Rijken (Gaubius Laboratory, TNO prevention and Health, Leiden, The Netherlands) for providing us with the antimannose receptor monoclonal antibody and Miss C. Limoge for proofreading the English manuscript.

\section{References}

Allaerts W, Tijssen AM, Jeucken PH, Drexhage HA, and de Koning J (1994). Influence of folliculo-stellate cells on biphasic luteinizing hormone secretion response to gonadotropinreleasing hormone in rat pituitary cell aggregates. Eur $\mathrm{J}$ Endocrinol 130:530-539.

Aust G, Hofmann A, Laue S, Ode-Hakim S, and Scherbaum WA (1996). Differential regulation of granulocytemacrophage colony-stimulating factor mRNA and protein expression in human thyrocytes and thyroid-derived fibroblasts by interleukin-1 alpha and tumor necrosis factoralpha. J Endocrinol 151:277-285.

Baes M, Allaerts W, and Denef C (1987). Evidence for functional communication between folliculo-stellate cells and hormone-secreting cells in perifused anterior pituitary cell aggregates. Endocrinology 120:685-691.

Bagriacik EU and Klein JR (2000). The thyrotropin (thyroidstimulating hormone) receptor is expressed on murine dendritic cells and on a subset of CD45RBhigh lymph node $T$ cells: Functional role for thyroid-stimulating hormone during immune activation. J Immunol 164:6158-6165.

Banchereau J, Briere F, Caux C, Davoust J, Lebecque S, Liu YJ, Pulendran B, and Palucka K (2000). Immunobiology of dendritic cells. Annu Rev Immunol 18:767-811.

Banchereau J and Steinman RM (1998). Dendritic cells and the control of immunity. Nature 392:245-252.

Bottazzo GF, Pujol-Borrell R, Hanafusa T, and Feldmann M (1983). Role of aberrant HLA-DR expression and antigen presentation in induction of endocrine autoimmunity. Lancet 2:1115-1119.

Caux C, Dezutter-Dambuyant C, Schmitt D, and Banchereau $J$ (1992). GM-CSF and TNF-alpha cooperate in the generation of dendritic Langerhans cells. Nature 360:258-261.

Caux C, Vanbervliet B, Massacrier C, Dezutter-Dambuyant C, de Saint-Vis B, Jacquet C, Yoneda K, Imamura S, Schmitt D, and Banchereau J (1996). CD34+ hematopoietic progenitors from human cord blood differentiate along two independent dendritic cell pathways in response to GM-CSF+TNF alpha. J Exp Med 184:695-706.

Cella M, Engering A, Pinet V, Pieters J, and Lanzavecchia A (1997). Inflammatory stimuli induce accumulation of MHC class II complexes on dendritic cells [see comments]. Nature 388:782-787.

Christensen PJ, Armstrong LR, Fak JJ, Chen GH, McDonald RA, Toews GB, and Paine R III (1995). Regulation of rat pulmonary dendritic cell immunostimulatory activity by alveolar epithelial cell-derived granulocyte macrophage colonystimulating factor. Am J Respir Cell Mol Biol 13:426-433.

Cochand L, Isler P, Songeon F, and Nicod LP (1999). Human lung dendritic cells have an immature phenotype with efficient mannose receptors. Am J Respir Cell Mol Biol 21:547554.
Contempre B, Le Moine O, Dumont JE, Denef JF, and Many MC (1996). Selenium deficiency and thyroid fibrosis. A key role for macrophages and transforming growth factor beta (TGF-beta). Mol Cell Endocrinol 124:7-15.

Croizet K, Rabilloud R, Kostrouch Z, Nicolas JF, and Rousset $B$ (2000). Culture of dendritic cells from a nonlymphoid organ, the thyroid gland: Evidence for TNFalpha-dependent phenotypic changes of thyroid-derived dendritic cells. Lab Invest $80: 1215-1225$

Drakesmith H, Chain B, and Beverley P (2000). How can dendritic cells cause autoimmune disease? Immunol Today 21:214-217.

Dumont JE, Lamy F, Roger P, and Maenhaut C (1992). Physiological and pathological regulation of thyroid cell proliferation and differentiation by thyrotropin and other factors. Physiol Rev 72:667-697.

Gabrilovich DI, Chen HL, Girgis KR, Cunningham HT, Meny GM, Nadaf S, Kavanaugh D, and Carbone DP (1996). Production of vascular endothelial growth factor by human tumors inhibits the functional maturation of dendritic cells. Nat Med 2:1096-1103.

Gabrilovich D, Ishida T, Oyama T, Ran S, Kravtsov V, Nadaf S, and Carbone DP (1998). Vascular endothelial growth factor inhibits the development of dendritic cells and dramatically affects the differentiation of multiple hematopoietic lineages in vivo. Blood 92:4150-4166.

Gabrilovich DI, Ishida T, Nadaf S, Ohm JE, and Carbone DP (1999). Antibodies to vascular endothelial growth factor enhance the efficacy of cancer immunotherapy by improving endogenous dendritic cell function. Clin Cancer Res 5:29632970.

Hala K, Malin G, Dietrich H, Loesch U, Boeck G, Wolf H, Kaspers B, Geryk J, Falk M, and Boyd RL (1996). Analysis of the initiation period of spontaneous autoimmune thyroiditis (SAT) in obese strain (OS) of chickens. J Autoimmun 9:129-138.

Hanafusa T, Pujol-Borrell R, Chiovato L, Russell RC, Doniach D, and Bottazzo GF (1983). Aberrant expression of HLA-DR antigen on thyrocytes in Graves' disease: Relevance for autoimmunity. Lancet 2:1111-1115.

Hart DN (1997). Dendritic cells: Unique leukocyte populations which control the primary immune response. Blood 90:32453287.

Heufler C, Koch F, and Schuler G (1988). Granulocyte/ macrophage colony-stimulating factor and interleukin $1 \mathrm{me}$ diate the maturation of murine epidermal Langerhans cells into potent immunostimulatory dendritic cells. J Exp Med 167:700-705.

Hoek A, Allaerts W, Leenen PJ, Schoemaker J, and Drexhage HA (1997). Dendritic cells and macrophages in the pituitary and the gonads. Evidence for their role in the fine regulation of the reproductive endocrine response. Eur $\mathrm{J}$ Endocrinol $136: 8-24$.

Inaba K, Inaba M, Romani N, Aya H, Deguchi M, Ikehara S, Muramatsu S, and Steinman RM (1992). Generation of large numbers of dendritic cells from mouse bone marrow cultures supplemented with granulocyte/macrophage colonystimulating factor. J Exp Med 176:1693-1702.

Jordens R, Thompson A, Amons R, and Koning F (1999). Human dendritic cells shed a functional, soluble form of the mannose receptor. Int Immunol 11:1775-1780. 
Kabel PJ, Voorbij HA, De Haan M, van der Gaag RD, and Drexhage HA (1988). Intrathyroidal dendritic cells. J Clin Endocrinol Metab 66:199-207.

Kasai K, Banba N, Motohashi S, Fukuda H, Manaka K, Matsumura M, Sekiguchi Y, and Hattori Y (1997). Production of granulocyte/macrophage and macrophage colonystimulating factors by human thyrocytes in culture. Biochem Biophys Res Commun 238:191-196.

Koch F, Heufler C, Kampgen E, Schneeweiss D, Bock G, and Schuler G (1990). Tumor necrosis factor alpha maintains the viability of murine epidermal Langerhans cells in culture, but in contrast to granulocyte/macrophage colony-stimulating factor, without inducing their functional maturation. J Exp Med 171:159-171.

Kolaja KL and Klaassen CD (1998). Dose-response examination of UDP-glucuronosyltransferase inducers and their ability to increase both TGF-beta expression and thyroid follicular cell apoptosis. Toxicol Sci 46:31-37.

Labarca C and Paigen K (1980). A simple, rapid, and sensitive DNA assay procedure. Anal Biochem 102:344-352.

Many MC, Maniratunga S, Varis I, Dardenne M, Drexhage HA, and Denef JF (1995). Two-step development of Hashimoto-like thyroiditis in genetically autoimmune prone non-obese diabetic mice: Effects of iodine-induced cell necrosis. J Endocrinol 147:311-320.

Martinez-Pomares L, Mahoney JA, Kaposzta R, Linehan SA, Stahl PD, and Gordon S (1998). A functional soluble form of the murine mannose receptor is produced by macrophages in vitro and is present in mouse serum. $\mathrm{J}$ Biol Chem 273: 23376-23380.

Masten BJ and Lipscomb MF (1999). Comparison of lung dendritic cells and $B$ cells in stimulating naive antigenspecific T cells. J Immunol 162:1310-1317.

Matsumura M, Banba N, Motohashi S, and Hattori Y (1999). Interleukin-6 and transforming growth factor-beta regulate the expression of monocyte chemoattractant protein- 1 and colony-stimulating factors in human thyroid follicular cells. Life Sci 65:L129-135.

Mooij P, Simons PJ, de Haan-Meulman M, de Wit HJ, and Drexhage HA (1994). Effect of thyroid hormones and other iodinated compounds on the transition of monocytes into veiled/dendritic cells: Role of granulocyte-macrophage colony-stimulating factor, tumour-necrosis factor-alpha and interleukin-6. J Endocrinol 140:503-512.

Morosini PP, Taccaliti A, Arnaldi G, Simonella G, Petrelli MD, Mancini V, Montironi R, Scarpelli M, Diamanti L, and Mantero F (1996). Enhanced expression of transforming growth factor beta1 in rat thyroid hyperplasia is thyrotropin induced and time dependent [see comments]. Eur J Endocrinol 134:373-378.

Ortner U, Inaba K, Koch F, Heine M, Miwa M, Schuler G, and Romani N (1996). An improved isolation method for murine migratory cutaneous dendritic cells. J Immunol Methods 193:71-79.

Pekary AE, Berg L, Wang J, Lee P, Dubinett SM, and Hershman JM (1995). TNF-alpha, TSH, and aging regulate TGF-beta synthesis and secretion in FRTL- 5 rat thyroid cells. Am J Physiol 268:R808-815.

Pierre P, Turley SJ, Gatti E, Hull M, Meltzer J, Mirza A, Inaba K, Steinman RM, and Mellman I (1997). Developmental regulation of $\mathrm{MHC}$ class II transport in mouse dendritic cells [see comments]. Nature 388:787-792.
Riedl E, Strobl H, Majdic O, and Knapp W (1997). TGF-beta 1 promotes in vitro generation of dendritic cells by protecting progenitor cells from apoptosis. J Immunol 158:1591-1597.

Roger PP (1996). Thyrotropin-dependent transforming growth factor beta expression in thyroid gland [see comment]. Eur J Endocrinol 134:269-271.

Sallusto F and Lanzavecchia A (1994). Efficient presentation of soluble antigen by cultured human dendritic cells is maintained by granulocyte/macrophage colony-stimulating factor plus interleukin 4 and downregulated by tumor necrosis factor alpha. J Exp Med 179:1109-1118.

Santambrogio L, Sato AK, Carven GJ, Belyanskaya SL, Strominger JL, and Stern LJ (1999b). Extracellular antigen processing and presentation by immature dendritic cells. Proc Natl Acad Sci USA 96:15056-15061.

Santambrogio L, Sato AK, Fischer FR, Dorf ME, and Stern LJ (1999a). Abundant empty class II MHC molecules on the surface of immature dendritic cells. Proc Natl Acad Sci USA 96:15050-15055.

Sato K, Yamazaki K, Shizume K, Kanaji Y, Obara T, Ohsumi K, Demura H, Yamaguchi S, and Shibuya M (1995). Stimulation by thyroid-stimulating hormone and Grave's immunoglobulin $\mathrm{G}$ of vascular endothelial growth factor mRNA expression in human thyroid follicles in vitro and flt mRNA expression in the rat thyroid in vivo. J Clin Invest 96:1295-1302.

Simons PJ, Delemarre FG, and Drexhage HA (1998). Antigenpresenting dendritic cells as regulators of the growth of thyrocytes: A role of interleukin-1beta and interleukin-6. Endocrinology 139:3148-3156.

Soh EY, Sobhi SA, Wong MG, Meng YG, Siperstein AE, Clark OH, and Duh QY (1996). Thyroid-stimulating hormone promotes the secretion of vascular endothelial growth factor in thyroid cancer cell lines. Surgery 120:944-947.

Steinman RM (1991). The dendritic cell system and its role in immunogenicity. Annu Rev Immunol 9:271-296.

Strobl H and Knapp W (1999). TGF-beta1 regulation of dendritic cells. Microbes Infect 1:1283-1290.

Viglietto G, Romano A, Manzo G, Chiappetta G, Paoletti I, Califano D, Galati MG, Mauriello V, Bruni P, Lago CT, Fusco A, and Persico MG (1997). Upregulation of the angiogenic factors PIGF, VEGF and their receptors (Flt-1, Flk-1/KDR) by TSH in cultured thyrocytes and in the thyroid gland of thiouracil-fed rats suggest a TSH-dependent paracrine mechanism for goiter hypervascularization. Oncogene 15:2687-2698.

Voorby HA, Kabel PJ, de Haan M, Jeucken PH, van der Gaag RD, de Baets MH, and Drexhage HA (1990). Dendritic cells and class II MHC expression on thyrocytes during the autoimmune thyroid disease of the BB rat. Clin Immunol Immunopathol 55:9-22.

Wang JF, Milosveski V, Schramek C, Fong GH, Becks GP, and Hill DJ (1998). Presence and possible role of vascular endothelial growth factor in thyroid cell growth and function. J Endocrinol 157:5-12.

Yamaguchi Y (1998). Developmental regulation by cytokines of bone marrow-derived dendritic cells and epidermal Langerhans cells. Microbiol Immunol 42:639-650.

Yamaguchi Y, Tsumura H, Miwa M, and Inaba K (1997). Contrasting effects of TGF-beta 1 and TNF-alpha on the development of dendritic cells from progenitors in mouse bone marrow. Stem Cells 15:144-153. 